\title{
Transcending Boundaries of Creativity: Active learning in the Design Studio
}

\author{
Mohamed Gamal Abdelmonem*
}

\author{
Queen's University Belfast, UK
}

\begin{abstract}
This essay investigates the changing dynamics of interaction and paradigm of communication in the design studio. It analyses the process of practical implementation of interactive tools in architectural education which placed the diversity of students' cultural experiences, contextual awareness and individual interests as crucial resource for design innovation and inquiry. Building on Brian Lawson's thesis on creativity in design thinking, this research project undertook comprehensive investigation of students' satisfaction of their roles in the studio and the room for liberal thought they are given to elaborate on genuine approach to architectural matters. The cyclical development of interactive learning strategy is explored through two different settings: first, it analyses architectural students' position as passive/active in the studio, considering their relationships with tutors' ideals; second, it reports on empirical strategy of students-led workshops at British schools of architecture, during which students have taken the lead of their creative design agenda. The practical implementation of interactive learning tools proved influential in helping students to personalize their design direction and to build a sense of confidence and independence.
\end{abstract}

Keywords: Interactive learning, studio pedagogy, learning by doing, Creative thinking, architecture education.

\section{INTRODUCTION: ON THE PEDAGOGY OF DESIGN STUDIO}

In his book How Designers Think: The Design Process Demystified Brian Lawson interrogated the design process as an enquiry about how the intuition and conceptual development through investigation and critical thinking is a valid research process [1]. Particularly intriguing in Lawson's inquiry is the openended question of objectivity of the design process; is Design a subjective or objective matter? Equally was the question about creativity; how to determine creativity and how to measure such cognitive process as design? Moving beyond these prescriptive set of measures, the design studio anticipates getting students' intuition, interest and knowledge at the center of a structured process of education in a forum of debate, exchange and critiques. The studio, hence, is a unique venue of negotiation between the explicit and the implicit; the power of decision making between the initiator and author (the student) and the negotiator (the tutor). The dialogue between the ambition and the critique drives the student's agenda [2].

Design as a process of education needs further interrogation. According to Lawson, design is 'a generic activity and yet there appears to be real difference between the end products created by designers in various domains' [1]. Design is a term that has often been tied to the various applied arts and engineering fields and production either as a noun (product), a verb

*Address correspondence to this author at the Queen's University Belfast, UK; Tel: +44(0) 782896 7919; E-mail: m.gamal@qub.ac.uk (act) or as an adjective (job description). As a verb, "to design" refers to "the process of originating and developing a plan for a product, structure, system, or component with intention' [3]. As a noun, "a design" is used for either the final (solution) plan (e.g. proposal, drawing, model, description) or the result of implementing that plan in the form of the final product of a design process. Being defined so broadly, no limitations exist and the final product can be anything ranging from socks, cars, fashion designs, to web designs and charts [6].

The process of design varies from the mathematical and systematic analysis of a structural engineer calculating loads on a beam, to the unpredictable and indeterminate process by which a fashion designer produces his collections. Within such a wide meaning and process of design, architectural students have to negotiate two extremes; "imagination and upredictable" from one side. Christopher Alexander considers the process of design as 'the process of inventing physical things which display new physical order, organization, form in response to function' [4]. Any architectural production requires imagination and creativity along with technical knowledge and expertise.

Architects, furthermore, are now more accountable to their society than most of their twentieth century counterparts. Participation of the public in decisionmaking for the built environment has become a priority on the political agenda and planning procedures. Despite being seen as a 'threat to the normative architectural values' [5], it is the main field of operation 
and the support of the public end-users is crucial. These situations are more dynamic, unpredictable and continuously changing according to the nature and context of the project [6]. This, moreover, implies that architects will need skills that enable them to comprehend the cultural and social aspects of their society and create strong connections between those aspects and their designs.

The design studio has, moreover, become more oriented towards mimicking the professional practice in response to the pressure of professional practice and market demands imposed on the curricula through professional accreditation bodies. Students' intellectual position within the wider theoretical discourses has, as a result, become a second priority following the professional skills of communications, drawings and representation [7]. The apparent lack of focus on active learning that helps students initiate own knowledge and reflect on personal experiences is best emphasised by Creig Crysler [8]:

\begin{abstract}
Architectural education is strongly biased toward what has been called the "transmission model" of pedagogy. This form of schooling sees students as a unitary body removed from ideological and material forces and thus "the same underneath it all" - blank screens ready to receive unmediated transmissions of skills and information as delineated by experts. The conception of an undifferentiated mass is central to architectural education because its primary goal is to produce a standardized product: a professional armed with a corpus of marketable skills.
\end{abstract}

Progressive deep learning methods offer students the opportunity to illustrate and reflect on different cultural experiences leading to the production of selfdriven and initiated model of knowledge-generation. Studio agenda becomes a venue for different possibilities and diversity of unpredictable outcomes. Driven by these polar positions toward the mission of the studio, this essay interrogates such cultural and social venue as a space for enquiry that addresses exploration, analysis and search for a spatial language. It further reports on experimental strategy and empirical work on active learning techniques. It argues that when students are given opportunities to explore and use their own experiences and cultural knowledge, creative and diverse ideas are the expected outcomes.

\section{CREATIVITY AND REPRODUCTION: DEEP LEAR- NING IN PERSPECTIVE}

"Knowledge disseminated in the design studio is often packaged in the form of precedents or generalizations drawn from, at best, a limited number of instances rather than from first principles. This is evident in virtually all texts, theses, treatises and papers on architectural education. Precedents in this sense are specific designs or buildings, which are exemplary in some sense, so that what architects and students glean from these examples, can support their own designs. These precedents are very often past solutions to specific design problems [9]".

Ömer Akin

Akin's perspective of educational process is prevalent in architectural schools; where the tutors are influential mentors throughout the Royal Institute of British Architects (RIBA\} accredited five-year programme [10]. Design projects are the chief device of learning-by-doing activities that progress in scale and complexity, each achieving gradual development of skills. The extensive use of precedent, in this sense, is a symptom of rigidity that does not address change in real life situations. What Akin depicted is the myth of innovation within the traditional design studio settings. 'Past solution', according to him, is peculiar to the original architect who operated in response to specific condition in the past, the adoption of which soon becomes a reproduction of the past process.

This is more obvious in design reviews, where students are receiving comments packaged in a series of precedents names or features, ending up with a library of specific designs for students to pick from. Tutors emphasize that the strength of an architect lies in his/her own library, basically the mental one. However, this library remains rather short of being resources of renewable creativity. What if such visual memory extends to include cultural knowledge, social awareness, and consciousness of certain values and issues of communication within society? Architectural students are often more creative through their ability to create connections between different cultural productions, such as music-architecture, architecture and dancing, architecture and theatrical movement [11-13]. 
But, the study of precedent is valuable resource to gain insights into case studies of creative process of design and understand how architecture is made of complex layers of work and engagement with technology and materiality, while trying to respond to social and cultural demands. This requires a dynamic mentality, searching for alternative approaches not products. In response, contemporary conventions divide the studio into sets of small group units, each of which is directed by a single tutor, whose interests and knowledge lead the design unit towards particular but conscious outcomes. Margaret Wilson's research reveals such a dilemma between the school preferences and certain styles emerging in students' production. She stresses such correlation indicates significant problems with the studio concept of design education [1]. Moreover, she concluded that architectural students are 'taught what to like'. In this paper, I argue that this model is insufficient for training architects with the dynamic mentality necessary for coping with changing situations. Rather, a studentcentered approach to design is the direction which architectural education needs to take. In short, students need to be trained as active learners through encouragement of enquiry-based learning tasks that allow them to practice independent as well as collaborative research and engage more with real situations and conditions of everyday life to build their custom-made knowledge [6].

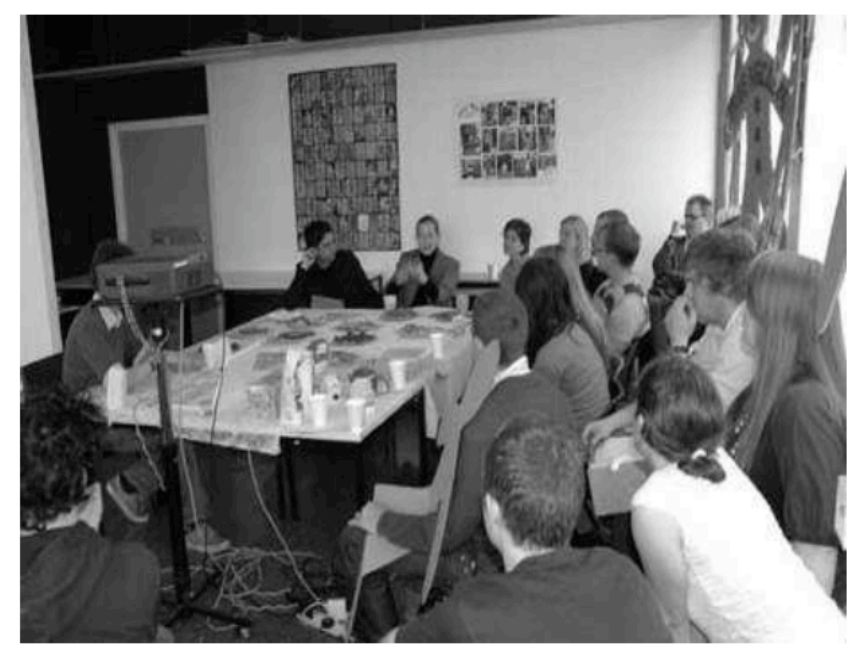

Figure 1: Current teaching setting in the studio: Students listen to tutor's talk on precedents.

\section{Photo by Peter Lathy (SSoA)}

But, 'is there such a thing as design knowledge?' Brian Lawson asked once in What Designers Know, in an attempt to uncover the complexity of knowledge, expertise and practice that come at work in the design studio [14]. Lawson goes into greater detail to investigate the practice of design and architecture, in an attempt to define what makes architecture more than the mere act of building. There is a high level body of knowledge, according to Lawson, that facilitates the emergence of architecture. While no prescriptive areas of knowledge that contribute to its production, design attributes to a cognitive process that generates within students minds, and cultural context. According to Reyner Banham, it is a 'Black Box'; that's a secretive profession, yet to be decoded [15].

At the core of student's approach to learning is the social context and setting within which students acquire their knowledge. While it has been suggested that enabling students to develop metacognitive expertise plays a major role in facilitating inquiry learning, collaborative work within particular social contexts and interactions is found essential to facilitate learning and development of thoughts [16]. Interactive Learning in this respect benefit from semi-structured agenda; first, to prepare the students for more open, self-motivated learning environments, in which the studio becomes more balanced setting in which the student gets more authorship of own work and decision making as the initiators; second is to encourage collaborative work and peer discussions, where students engage and benefit from each other.

'Because of the predominating impact of studio, student experience of studio pedagogy is central to understanding their interpretations of architectural education' [17].

Groat \& Ahrentzen.

\section{FROM THEORY TO PRACTICE: SHIFTING THE DEEPLY-ROOTED SYSTEM}

The current situation suggests that the tutors' knowledge and experience are the basic source of guidance within the studio. Thus, with a class of around 60 students and diverse experiences and personalities, including cultural backgrounds, interests and capabilities, the situation is obviously unbalanced and does not allow innovation and creativity to capitalize on broad and diverse proposals and ideas. This is practically redressed if we start to flip the situation and use the students as informants and as a source of knowledge: while tutors develop their roles as elaborators and enhancers (Figure 5). This would be a 
positive step in the creation of a more innovative, liberated and creative design environment. It would intertwine the students' personal interests with their academic training, which suggests, according to Craig Crysler, more engagement between the human and the student in the cognitive sense of the interactive Learner.

While Spiro Kostof defines architecture to include social, economic and political imperatives, Hannes Mayer, once the head of the Bauhaus at Dessau, defines it as a process of giving form and pattern to the social life of the community. Within such a strong relation between architecture and its context lies the provoking idea that conceives the human being as an informative resource for the architect within. This strategy suggests that uniting the personal' and the professional' would enrich and empower the process of training a creative, open-minded and socially engaged architect.

A proposal was made, utilizing enquiry-based learning initiatives, which was based on the principle of using real-world problems as a starting point for the acquisition and integration of new knowledge, denoting students as interactive researchers who channel their personal interests and knowledge into design research. The use of theoretical debates and research as initiator of design intuition works as a collaborative production of knowledge that is based on autonomous research activity of each student: who needs to interpret own cultural resources and experiences into a very limited text to present to and debate with peers. This organization builds on the 'reciprocal teaching' strategy, which includes explanatory activities, that has dramatically improved the student's comprehension as well as monitoring skills in other fields. Studies suggest that participating in explanatory activities in social situations improves students' learning.

Students were at liberty to explore resources and material they think suitable for the topic they discuss. They need to construct their views, reflect their ideas, and present their individual perspectives to their colleagues in a communicative medium. Each student is requested to submit a concise essay/text which presents particular understanding of architecture as a practice. Every essay includes a point of reference that represents the student's vision. This develops throughout the course of the project evolution to instil design ideals and own character.
4. CHALLENGING THE BOUNDARIES: ARCHITECTURAL STUDENTS AS INTERACTIVE LEARNERS

Virtually all architecture programs organize their curricula in terms of a design studio as a centerpoint model, with a constellation of support courses required and/or available to augment the integrative activities assumed to take place in studio. Because of the predominating impact of studio, student experience of studio pedagogy is central to understanding their interpretations of architectural education. [17]

\section{Groat \& Ahrentzen}

While it has been suggested that enabling students to develop metacognitive expertise plays a major role in facilitating inquiry learning, collaborative work within particular social contexts and interactions is found essential to facilitate learning and development of thoughts [18]. At the core of this process is creating active classrooms and studio communities that embody constructivist approaches to learning [19]. In order to introduce a more interactive approach to architectural education, there will be a need to develop learning environments to encourage collaborative work and peer discussions. White \& et al. argued that 'young students need to develop conscious, explicit theories of the cognitive and social processes needed for learning. Such awareness can enable them to engage in reflective conversations about the nature, purpose, and utility of these processes and to thereby come to understand them better, use them more effectively, and improve them'. White's argument suggests that, in the early years, students can easily develop processes of learning, and can diversify the levels of communication, argument and reflective thinking. Therefore, the focus needs to be on early years students, mainly, first and second year undergraduates.

To emulate real conditions of design and to contribute to the broader issues of society, design tasks have been oriented towards engagement with real clients in what is becoming known as Live Project. Real engagement with clients was a process of training on communications, negotiations and awareness of everyday life realities and an attempt to respond to concerns over the failure of architects to develop interpersonal skills during their undergraduate studies [20]. Emerging professional environments and standards of work as a result of the Live Projects informed the design agenda of the past decade. Yet, it 
has its limitations with regard to the development of the students' cognitive processes as interactive learners. Educational pedagogy in other subjects suggests that the students' pre-knowledge and experiences could contribute significantly to their learning processes [21]. In architecture, through interpretation of socio-cultural contexts, students is well positioned to come up with innovative design that are diverse than what a tutorcentred approach may offer.

However, such a proposition raises certain issues for consideration. The tutor-centred teaching is normatively loaded with ideals, positions and prejudice towards architectural schools and dismissing others. The neutral or influence-free teaching environment is largely absent. One strategy is to allow for student-led reviews to gain more weight in the evaluation process. Although this serves to assess the outcome of the process, rather than liberating the process itself, it remains a serious attempt to balance power politics within the studio. Another strategy, which this paper suggests, is to organize student-led workshops which depend basically on the students' input and contribution. In this context tutors might be observers, not participants. Students should be free to give their insights, participate in debate and challenge each other's views without the involvement of their tutors. This is a familiar approach of 'self and peerassessment' which, according to Nicol and Pilling, helps students to develop their skills for lifelong learning [22]. The exploration of how this strategy would contribute to students' innovation and selfdevelopment could establish a fresh vision into architectural education and could resemble a radical shift what has been deeply-rooted, yet traditional design studio.

To overcome lack of confidence and interpersonal skills amongst early year students, proposed tools would focus heavily on interactive and reciprocal communications and learning activities. They utilise purposely-designed workshops to facilitate studentparticipant to build on acquisition of a student group's collective expertise, critiques and feedback. They empower students to talk and communicate about buildings, feelings, ideas, perceptions and experiences. Students will then learn that own experiences, as active citizens, are rich material to bring novel vision and discourses to tutorials. From the pedagogical perspective, as a cultural and technological artifact, should engage more effectively with cultural context and social reality and the only agency for that is that of the architectural students' everyday life and experiences. The design studio should no longer act as an isolated universe inside which students are trained as industrious professionals in isolation from the reality of their daily social world [23].
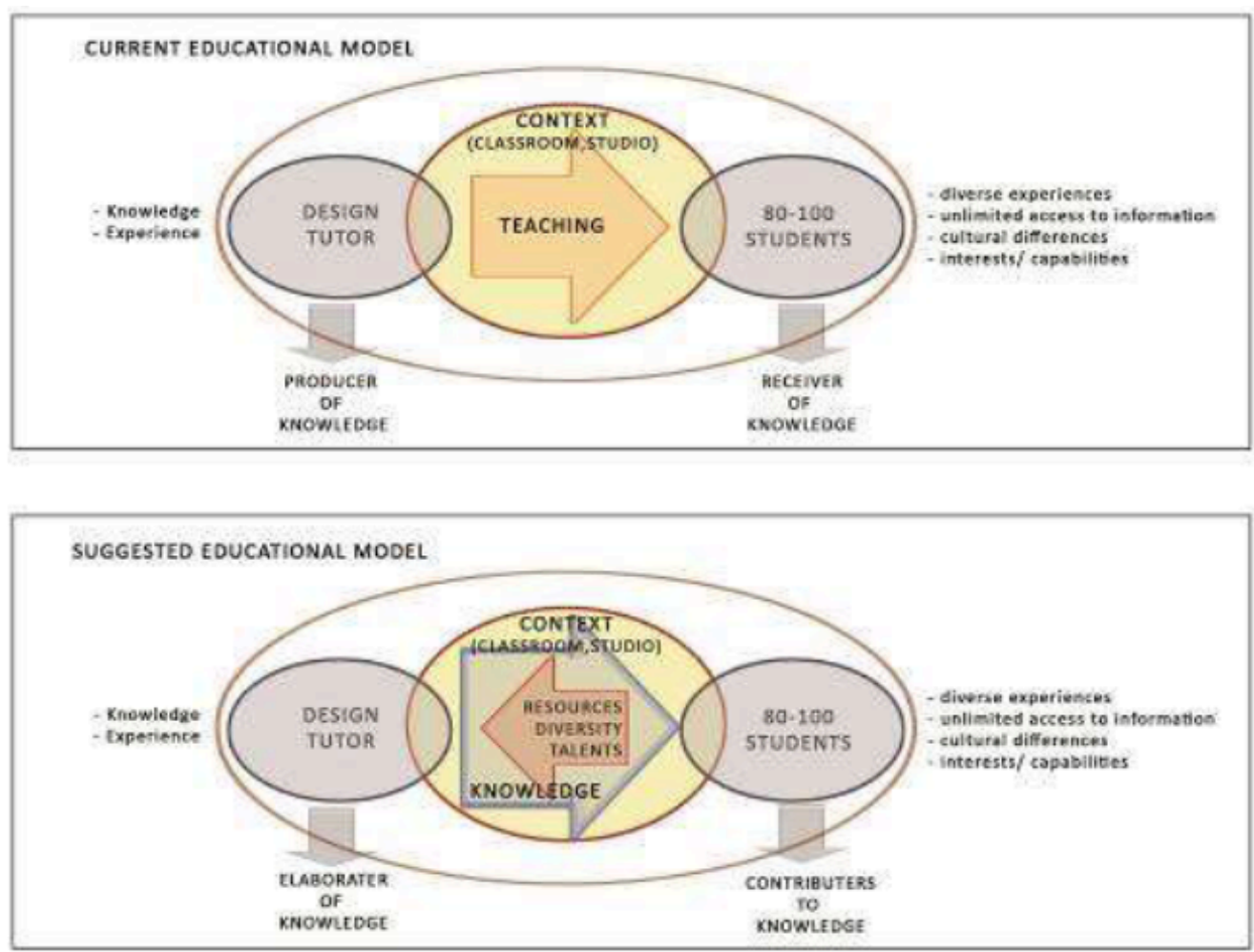

Figure 2: Current and suggested model of Communication in the studio. 


\section{FROM THEORY TO PRACTICE: SHIFTING THE DEEP-ROOTED SYSTEM}

Proposed student-led workshops require no preliminary reading or work. Students' take part in casual settings that facilitated relaxed communications and open-ended discussions; no prerequisite, milestone. Rather, the social context is the exact opposite to the tense and pressure-laden design studio and that challenges the boundaries and imbalance of the tutor-student commanding positions. This structure was developed with undergraduate students at SSoA and out of previous study on the propagation of Ideologies in the Design Studio. There has been a broad feeling that certain political ideology is implicitly imposed on the students throughout schools' curricula and training programmes. Students, throughout individual interviews, described this as a threat to their independence and freedom of choice [24]. Rather than being considered as empty pots to fill, students are looked at as members of society with autonomous ideologies and experiences that should be allowed to evolve and thrive within the studio. The diversity of experiences and background knowledge, in this sense, are invaluable resources that have developed throughout pre-university years; rather than being controlled and replaced with professional ideals.

It aimed to test whether or not students' creative contributions to design ideas could be more diverse and unpredictable in the absence of their tutors. What would happen, if students could be empowered to become the source of knowledge in the studio. This can be redressed if we start to flip the situation and use the students as informants and as a source of knowledge: while tutors develop their roles as elaborators and enhancers (Figure 2). This would be a positive step in the creation of a more innovative, liberated and creative design environment. It would intertwine the students' personal interests with their academic training, which suggests, according to Craig Crysler, more engagement between the human and the student in the cognitive sense of the interactive Learner. It, moreover, would enable them to contribute to their studies, be independent learners and develop their intellectual skills of interpretation and connection between academia and real life experiences. In short, they need to be producers of knowledge rather than its consumers.

At the core of this strategy is understanding architecture as a product of culture and socio-spatial systems of living: within which real life experiences and individuals are effective players in shaping the built environment. The radical view of architecture as an elite field of study is no longer affordable. While Spiro Kostof defines architecture to include social, economic and political imperatives, Hannes Mayer, once the head of the Bauhaus at Dessau, defines it as a process of giving form and pattern to the social life of the community [25]. Within such a strong relation between architecture and its context lies the potential success of the suggested approach, which conceives the human being as an informative resource for the architect. This strategy suggests that uniting the personal' and the professional' would enrich and empower the process of training a creative, open-minded and socially engaged architect.

\section{INTERACTIVE LEARNING IN ACTION}

There is a growing understanding that workshops work as an effective tool of generating knowledge exchange and effective engagement that traditional lecture or design studio situations could not provide [26]. A workshop was proposed for the second year undergraduate students to start alongside the design project, whose focus is the design of a home. It was announced on a quest to help them develop ideas and thoughts for their design task [27]. It covered the notion and the idea of home that aimed at cognitive processing of own background to generate initiatives and thought provoking concepts. It worked at the level of underlying cognition, rather than the explicit process of production.

To put this strategy into action, certain investigations were needed.

- $\quad$ Students' level of study and appropriate subject.

- $\quad$ Type of projects that could relate to the students previous knowledge and experience.

- $\quad$ How can we relate the desired knowledge to the immediate cultural context?

- $\quad$ How can this workshop be interesting enough to get the students involved actively?

The workshop required an elementary knowledge of drawings and architectural principles, and, therefore, following comprehensive discussions, second year students were chosen to work in small groups of 20-30 students. The workshop was split into three parts and was three hours long in total. It started with an introductory presentation to address the topic and its 
principal ideas, followed by an open discussion forum. During the second part, students were grouped into fives, and given a particular aspect to look at, investigate and explore. The third part comprised the review: students were to present their discussions to their colleagues - examiners. After every group presentation and discussion, the audience (students) was requested to grade their colleagues' work, using a standard assessment sheet. While the tutors were invited, they were to be no more than observers, not participants.

It is inappropriate to overlook the fact that such student-led situations could deviate from the anticipated route. It was realized that the shift in the social settings had to be gradual; a continuous process of negotiation, before, during and after the workshop. To avoid any contradiction with the current teaching settings, the workshop was started by the traditional means of an introductory but short presentation. Materials and examples across cultures and history were used to address the diversity of knowledge and its resources. Moreover, there were defined aspects for students to research and discuss across space (location, culture, language) and time (past, present, future).

Student feedback was found in favour of the introduced change to the structure, flexibility and freedom in the workshop: with which many students were not familiar. They particularly appreciated the variety of content, ideas and the interaction, branding it as relaxed and thought provoking. They did, however, find it quite vague, lacking in conclusion, specific detail and visual examples. They reflected the need to be prepared and to bring materials into the discussion. In line with the explorative scope, feedback forms were distributed, asking students to address two positive and two negative points from every part of the workshop [27]. Informative comments arose from two issues: first, the limited time provided for them to generate their ideas and discuss them without prior preparation. The second was the lack of visual materials that would have helped the students to clarify their ideas and give visual examples (important in architectural education).

\section{STUDENT'S BOOK OF IDEAS: INTERACTIVE PRODUCTION OF KNOWLEDGE}

Building on students' feedback, the workshop was developed into a set of prolonged activities that promoted students as producers of knowledge. A refined proposal, utilizing enquiry-based learning initiatives, was based on the principle of using realworld problems as a starting point for the acquisition and integration of new knowledge [28]. It denotes students as interactive researchers who channel their personal interests and knowledge into design research. The refined format works as a collaborative production of knowledge that is based on autonomous research activity of each student: who needs to interpret his/her own cultural resources and experiences into a very limited text to present to his/her colleagues. This organization builds on the 'reciprocal teaching' strategy, which includes explanatory activities, that has dramatically improved the student's comprehension as well as monitoring skills in other fields [30]. These studies suggest that participating in explanatory activities in social situations improves students' learning.

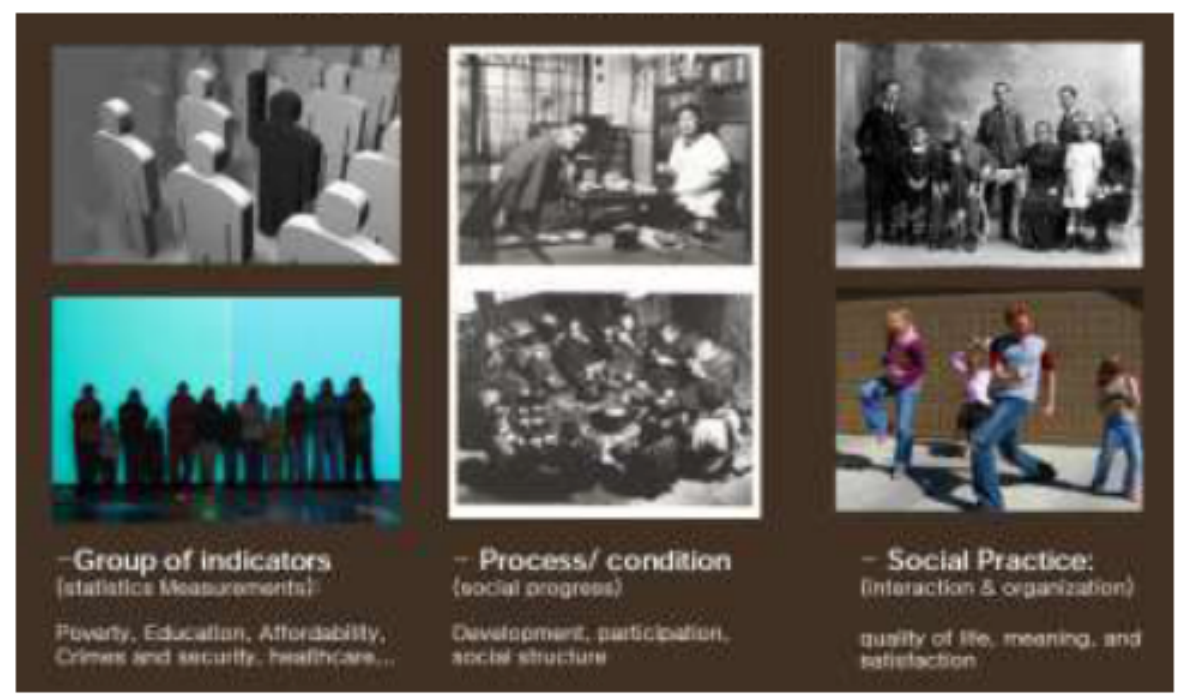

Figure 3: Examples across cultures and history: Extract from the introductory presentation. 
In the suggested organization, students are free to utilize the source material they think suitable for the topic they discuss. Each student is requested to submit a single A4 sheet of critical and concise essay/text which presents his/her understanding of the topic through the investigated material. Every essay should, typically, include one picture (visual) that represents the student's view/used material. The material could be a book, a journal article, a movie, a painting, a statue, or a photo. The essay should target a particular side of the investigated idea and reflect the student's personal view. While the belief is that students are limited in their ability to produce highly organized papers, what matters here is the process of production. The exercise is a practical tool to provide the student with the responsibility and evidence by giving him/her the opportunity to build his/her own perspective of things, while getting involved in an architectural debate of the wider cultural context and its interpretation.

For first year students, a relatively advanced project to design a space for contemplation was selected as a platform for the practical implementation of this refined organization. In the first week of the project, every student was asked to prepare a single A4 sheet that displayed, using one piece of visual material and one paragraph, each student's previous experience of being in a shelter or a space of contemplation. Neither examples nor references were given. The essayparagraph had to communicate why the selected material/space was relevant to the student and how it expressed the process of contemplation. Students were divided into sets of 25 for workshops, within which, groups of five students/groups were assembled. Every student was given one minute to speak about his/her selection and the rationale behind it. Then, groups swapped A4 sheets and analyzed different aspects through which students' materials addressed the notion of contemplation and shelter. At the end, every group presented their analysis of peers' work and the authors were given the chance to challenge/debate these analyses.

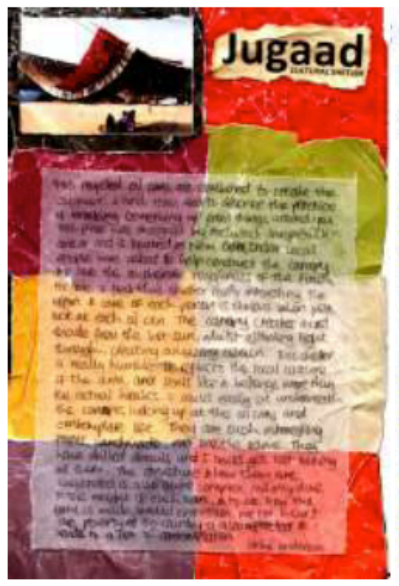

A

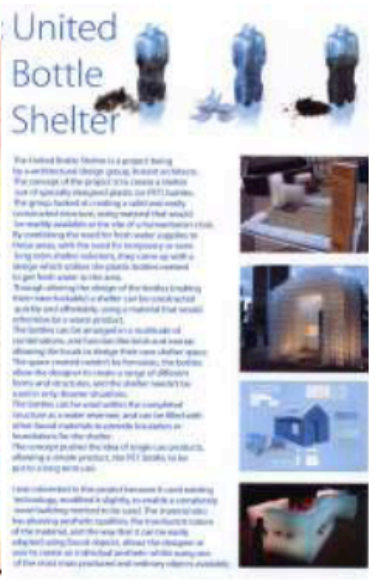

B

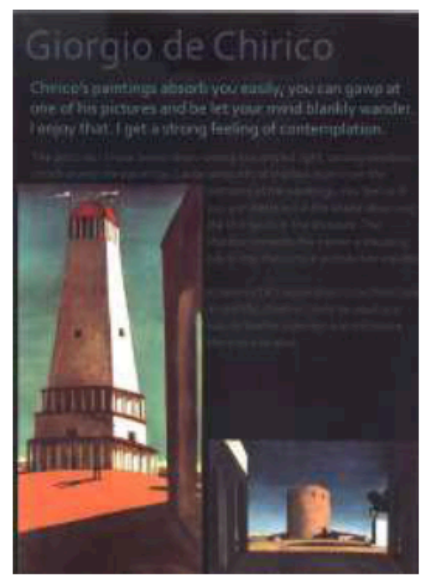

C

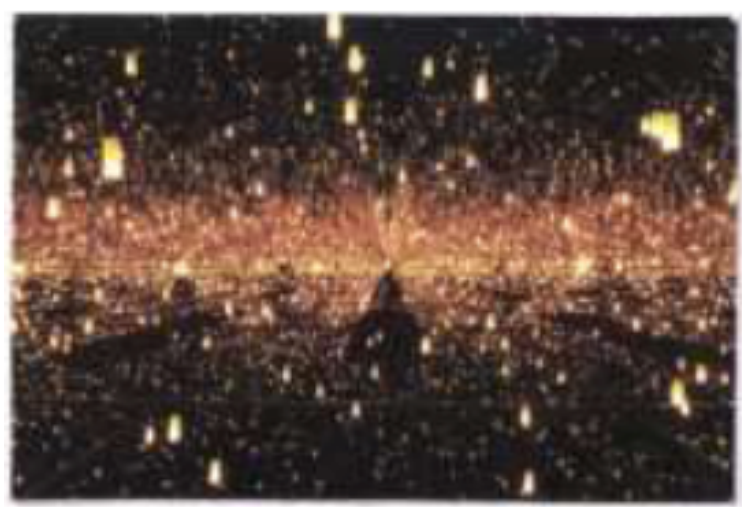

D

Figure 4: Examples of students' ideas/A4 sheets. A: Outdoor theatre of recycled oil-cans, India. B: Interlocking bottle shelter for humanitarian crisis. C: Paintings of Giorgio de Chirico. D: Infinity room. 
Discussions and debate were inclusive of a wide range of resources and concept-generative examples. With around 65 students attending, there were 65 different ideas and examples that crossed geographical sites from India and China in the east, to Norway (north) England and the United States (west). Spaces explored ranged from recycled oil can structures, recycled bottle envelopes, spaces of infinity, drainage pipes as a resource for children and natural landscapes (trees, and gardens) as a respite from the congestion of modern life. The range of products, critically and arguably, addressed the majority of contemporary architectural discourses, yet was produced by first year students with limited architectural knowledge (Figure 4).

At the end of the workshop all student sheets were collated to form the first Student's Book of Ideas: that included their individual sheets, photos, and group discussion pin-ups. A hard copy of the book was kept in the studio for frequent consultation and a digital copy was loaded onto the course online resources. Anonymous investigation confirmed that students had frequently consulted it throughout the project, and their tutors had perused its contents. Having such a studentproduced reference book contributed to the diversity and broadness of their visual and conceptual resources. The book summoned a range of influences, ideology-free, interactive research and communicative tasks and activities that helped students explore their cognition of spaces and people's experiences of those spaces. This was designed to help students to understand, at an early stage, the consequence and impact of architecture on the users and general public.

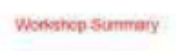

YEAR ONE

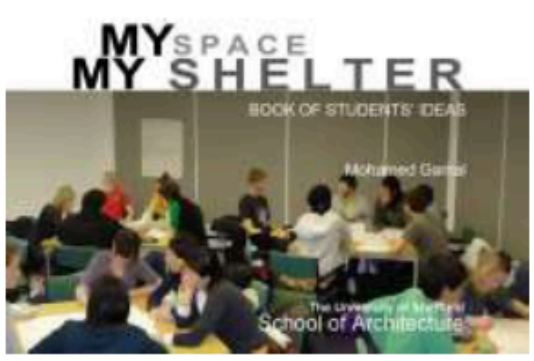

Figure 5: My Space My Shelter, Book of Students' Ideas. Left: Book cover; Right: student's pin-ups.
This was directly reflected on the diverse range of ideas communicated during design tutorials and helped to kick-start a meaningful and thoughtful conceptualization of architecture.

The impact of this form of learning activity is sought via two means: The first was direct communication and focused on group discussions after final design reviews with students and tutors to elaborate on the experience and its contribution. The second was an attempt to draw tentatively on the diversity and innovative aspects displayed in the final design submissions. The latter method, however, does not intend to draw absolute and discrete conclusions about the quality of end products. Rather, it attempts to explore the relative diversity and broadness of student ideas and concepts in comparison with previous, traditionally run projects.

Tutors were confirmed that students have become more confident, critical and thoughtful about what they propose or draw on paper. Students, on the other hand, were more explicit about how the new format helped them to discover the relevance of design tasks and architecture in general to their personal knowledge and everyday life experience. They were pleased to discover new aspects of the discussed topic that their colleagues addressed and which had not occurred to them. They believed that having similar workshops and student meetings at the beginning of every project would enable students experiencing difficulty in coming up with innovative ideas to learn and develop their own approach without a sense of shame or guilt.
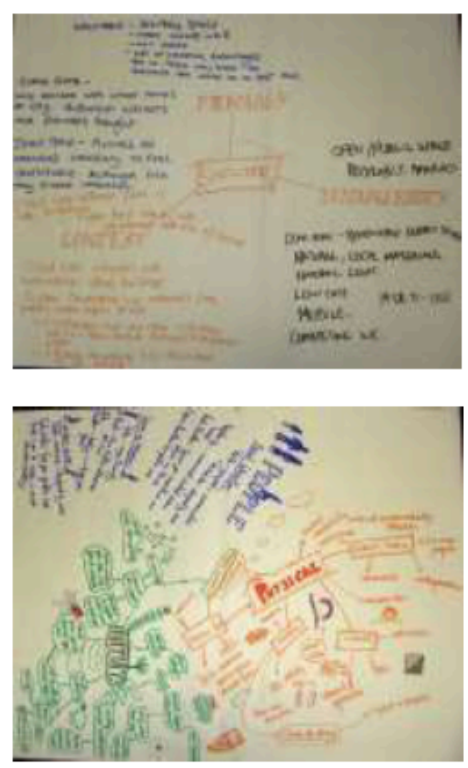

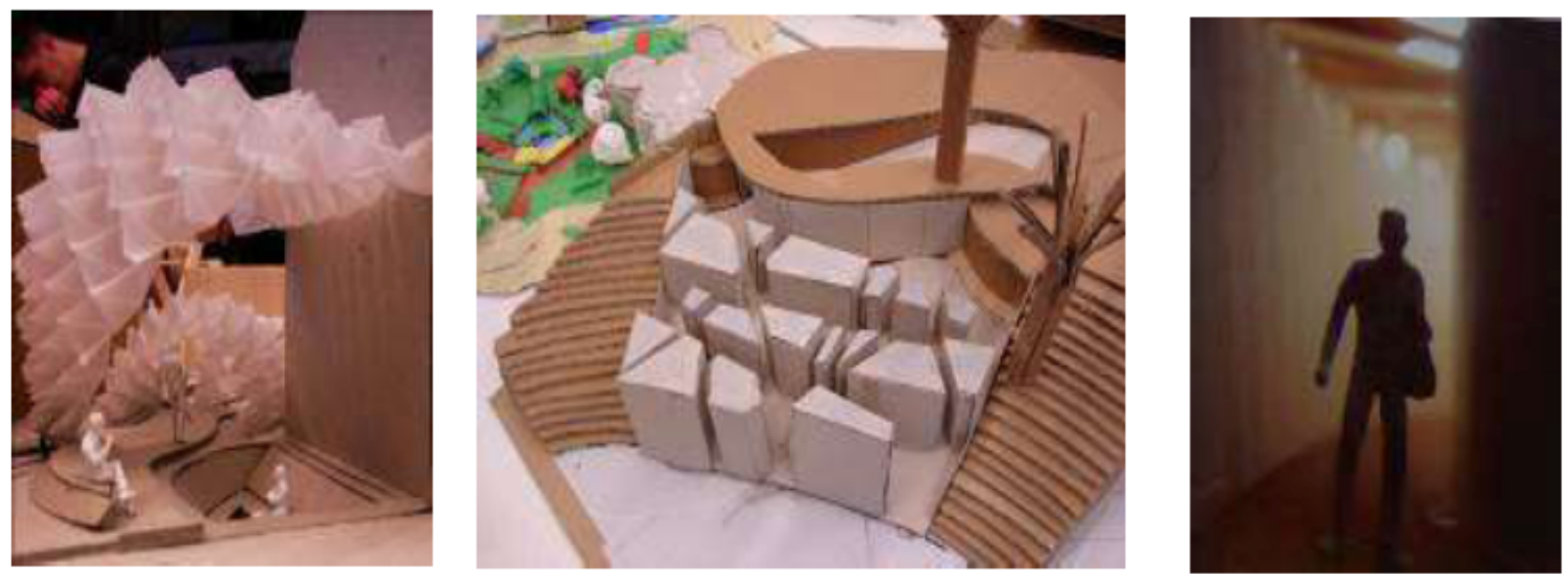

Figure 6: Examples of student' final design outcome representing diverse approaches to contemplation.

On the level of design outcome, students were able to provide a relatively wide range of concepts and developed designs that were in line with the diversity of resources exhibited in their book of ideas. While the design programme and site were similar in several student groups, designs were diverse enough to be categorized under a few principal ideologies or conceptual orientations. Final designs ranged from integration with existing natural context to design of sustainable structures and consciousness of the importance of the material. Most importantly, most design proposals addressed the experiences of the users as a central aspect around which their projects were (Figure 6).

\section{THE WAY FORWARD: ARCHITECTURE AND INTERACTIVE PARTICIPATION IN LEARNING}

The notion of enquiry-based learning focus on 'learning stimulated by inquiry and driven by research problems'. It requires minimum preparation from the students' side [31]. It was a 'structured inquiry', where the author provided an issue or problem and an outline for addressing it. This is demonstrated in the defined missions, and questions to be answered by different groups. Students were asked to reflect on their own experiences during the discussion forums. The second set of activities, which evolved from the first, required them to generate their individual and concise contributions to the collective knowledge in relation to one particular topic/notion, without giving details or questions. While movement from the structured to the unstructured format was studied and coordinated with design tasks, students were usually more comfortable with the second setting. Students' efforts reflected their ability and willingness at this stage to engage with open-ended tasks and critical discussions and investigation: which requires a redefinition of learning objectives at this level.

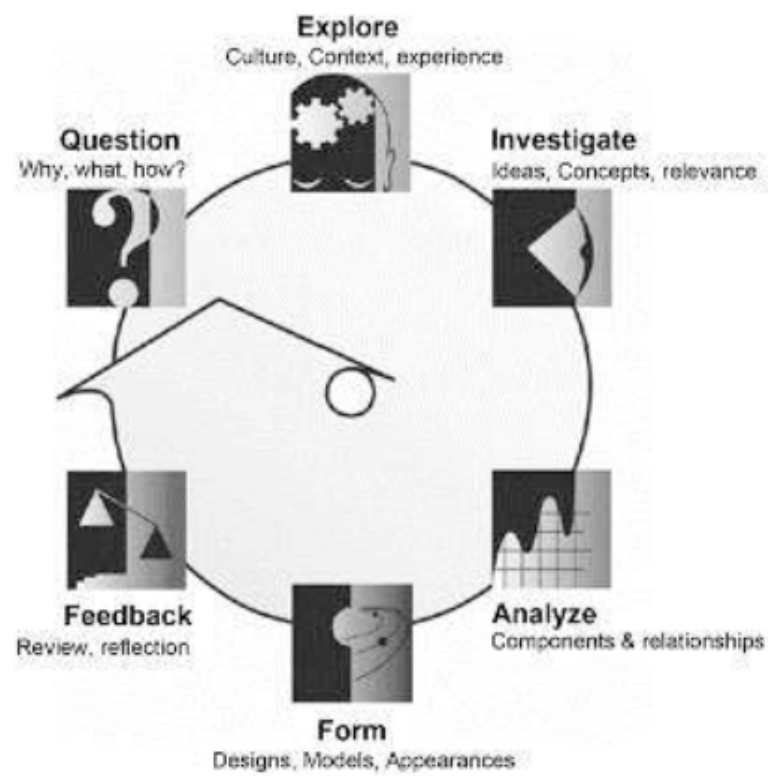

Figure 7: The Inquiry-Learning Cycle in Architectural Education.

(After White\& et al. 1999: 154)

Students proved their ability to generate and extend resources and ideas beyond the range expected to be promoted by their tutors and at times were more radical than mainstream design education and moving beyond the mere physical appropriation of the spatial experiences [32]. However, direction from tutors became crucial to help them develop these ideas into meaningful and accomplished design outcomes. This correlates, although indirectly, to the diversity and innovation that became visible in the final design presentations. Finally, students' interaction, learning environments and social engagement within the studio has considerable and lasting impact on their 
confidence and communication skills: both of which are crucial elements in improving their skills for independent learning in their post-university professional development as independent architects and learners in the long term.

At the student's cognitive thinking level, the findings suggested that practically-based strategies were informative in terms of allowing them the space to relate their personal reading to their cultural and social contexts and their learning and practice of architecture. In this respect, students' failure to come up with innovative ideas, as consistently reported in the first and second years, could be replaced by confidence and deep understanding of the mission of design. Students are more interested in exploration and discussions than in listening to lengthy lectures or even watching a customized display of images, videos or buildings. In line with recent challenges and agendas for higher education, it has become a realistic target to revisit the current studio setting: that has remained largely unchanged (despite a few alternative tools) throughout the past century in the face of many changes in knowledge, information technology and communication.

\section{THE WAY FORWARD: ARCHITECTURE AND INTERACTIVE PARTICIPATION IN LEARNING}

New challenges and continuous changes in the professional requirements of being an architect are continuing at an unprecedented pace to be accommodated into traditionally organized educational programmes. The skills of independent learning, communication and self-motivation, are essential to future architects: who need flexible and adaptable educational programmes that incorporate provisions for fast changing socio-cultural concerns and issues. These provisions could be accommodated in current programmes by engaging students in their process of academic training as contributor-researchers rather than listeners/replicators. Building on developing students' own knowledge, experiences and ideologies would appear to be more effective and creativityenhancing and give them the freedom to shape their own line into their practice. Encouraging interactive learning in architecture will move many students outside their secure, closed box of rigid and prescriptive courses, into more diverse and creative social environments. Attention should be focused on the student's personal development as a knowledgeseeker and as a researcher rather than informationholder. This disposition is essential to innovation and creativity in architectural education or as Jeremy till stated: 'Architecture depends' [33].

On the other hand, changing or altering a deeply rooted system is not an easy task to accomplish and not to be undertaken in haste. To introduce such flexibility and change within an educational context, different cycles of study, testing and modeling need practical investigation, testing and development. With the transition from a directed-teaching approach to interactive-learning mentality, students tend to appreciate the new context, but find it hard to build upon its relatively relaxed structure and environment. Tutors, on the other hand, tend to retain their authoritative and influential position within their studios. Therefore, the success of such a lengthy process of change lies in the understanding of the current situation, gaining the support of involved actors, and being sufficiently flexible to alter and develop implemented strategies.

\section{REFERENCES}

[1] Lawson B. How designers think: The design process demystified. London: Elsevier 2006.

[2] Abdelmonem MG. Portrush: Architecture for the North Irish coast. Belfast: Ulster Tatler 2013.

[3] Cambridge Dictionary of American English.

[4] Alexander C. Notes on the Synthesis of form. London: Harvard University Press 1979

[5] Till J. The negotiation of hope. In: Blundell Jones P, Till J, Petrescu D, editors. Architecture and participation. London: Taylor and Francis 2005; 23-42.

[6] Abdelmonem MG. The architecture of home in Cairo. London: Ashgate 2015.

[7] Prue Chiles in an interview in the Architect's Journal (2008) referred to the complaints of local practices that the schools of architecture do not provide their graduates with essential skills to suit their future professional needs in real life practice

[8] Crysler CG. Critical pedagogy and architectural education. JAE 1995; 48 (4): 208-217.

[9] Akin Ö. Case-based instruction strategies in architecture. Design Studies 2002; 23 (4): 407-431. http://dx.doi.org/10.1016/S0142-694X(01)00046-1

[10] Royal Institute of British Architects (RIBA) is the Official Accreditation body for all architectural schools in the UK.

[11] Lawson B. The language of space. London: The Architectural Press 2001

[12] Eisenbach R. Placing space: Architecture, action, dimension. JAE 2008; 61(4): 67-83.

[13] Khan O \& Hannah D. Performance/architecture (Interview of Bernard Tschumi). JAE 2008; 61 (4): 52-58

[14] Lawson B. What designers know. Oxford: Architectural Press 2004.

[15] Banham R. A Black Box: The Secret Profession of Architecture. In: A Critic Writes, editor Banham Berkeley: University of California Press 1996.

[16] Metacognition also refers to a 'level of thinking that involves active control over the process of thinking that is used in learning situations'. Planning the way to approach a learning 
task, monitoring comprehension, and evaluating the progress towards the completion of a task: these are skills that are metacognitive in their nature. For more details see: Janet Metcalfe \& Arthur Shimamura, Metacognition: Knowing about Knowing. (Cambridge, MA: MIT Press, 1994).

[17] Groat LN. Ahrentzen S. Reconceptualizing architectural education for a more diverse future: perceptions and visions of architectural students. JAE 1996; 49 (3): 166-183.

[18] White B, Shimoda TA, Frederiksen JR. Enabling students to construct theories of collaborative inquiry and reflective learning: Computer support for metacognitive development. IJAIED 1999; (10): 151-182.

[19] Okada T, Simon H. Collaborative discovery in a scientific domain. Cognitive Science 1997; 21(2): 109-146. http://dx.doi.org/10.1207/s15516709cog2102 1

[20] Torrington J. The development of group-working skills and role play in the first-year architecture course. In: Nicol D, Pilling S, editors. Architectural education and the profession: Preparing for the future, In Changing architectural education. London: Spon Press; 2000: 72-84.

[21] Butler J. From didactic expert to partner in learning. In: O'Reilly C, Cunningham L, Lester S, editors. Developing the Capable Practitioner. London: Routledge; 1999: 33-42.

[22] Nicol D, Pilling S. Architectural education and the profession: Preparing for the future, In Changing architectural education. London: Spon Press; 2000.

[23] Abdelmonem MG. The Architecture of Home in Cairo: Sociospatial practice of the Hawari's everyday life. London: Ashgate 2014.

[24] Abdelmonem MG. Propagation of ideologies in architectural education. 2008 Annual PCHE Conference, Sheffield, United Kingdom. Sheffield: Sheffield School of Architecture 2009.
[25] Worthington J. The changing context of professional practice. In: Nicol D, Pilling S, editors. Architectural education and the profession: Preparing for the future, In Changing architectural education. London: Spon Press 2000; 22-33

[26] Interview with a second year coordinator at Sheffield School of Architecture. UK, during February 2009.

[27] Within the dominant context within which the students are passive receivers, students do not appear to engage in any non-compulsory activity unless they know it could inform their design/assignments directly.

[28] Asking for negative comments was 'a brave act', as the course coordinator states. It aimed to inform the students that negative comments are as important as the positives: and both should help develop the organization. It is on the implicit issues that feedback from students is critical, even if it is negative.

[29] Kwan A. Problem-based Learning. In: Tight M, Mok KH Huisman J, Morphew CC, editors. The Routledge International handbook of higher education. London: Routledge 2009; 91-108.

[30] Okada T, Simon H. Collaborative discovery in a scientific domain. Cognitive Sciences 1997; 21(2): 109-146. http://dx.doi.org/10.1207/s15516709cog2102 1

[31] Spronken-Smith R. Designing courses with strong links between teaching and disciplinary research. Un-published Workshop, (Sheffield: CILASS unit, the University of Sheffield) took place on 11th March 2009.

[32] Refer to Peter HÜbner's winning proposal for community housing and facilities competition in 1990s' Germany. See, Blundell Jones P. Peter HÜbner: Building as a social process. London: Edition Axel Menges 2007.

[33] Till J. Architecture Depends. Cambridge: MIT Press 2009.

\section{DOI: http://dx.doi.org/10.15377/2409-9821.2014.01.01.5}

(c) 2014 Mohamed Gamal Abdelmonem; Avanti Publishers.

This is an open access article licensed under the terms of the Creative Commons Attribution Non-Commercial License (http://creativecommons.org/licenses/by-nc/3.0/) which permits unrestricted, non-commercial use, distribution and reproduction in any medium, provided the work is properly cited. 